\title{
User-Centered Guidance for Engineering and Design of Decentralized Sanitation Technologies
}

\author{
Laura Morrison, Anushah Hossain, Myles Elledge, Brian Stoner, and Jeff Piascik
}

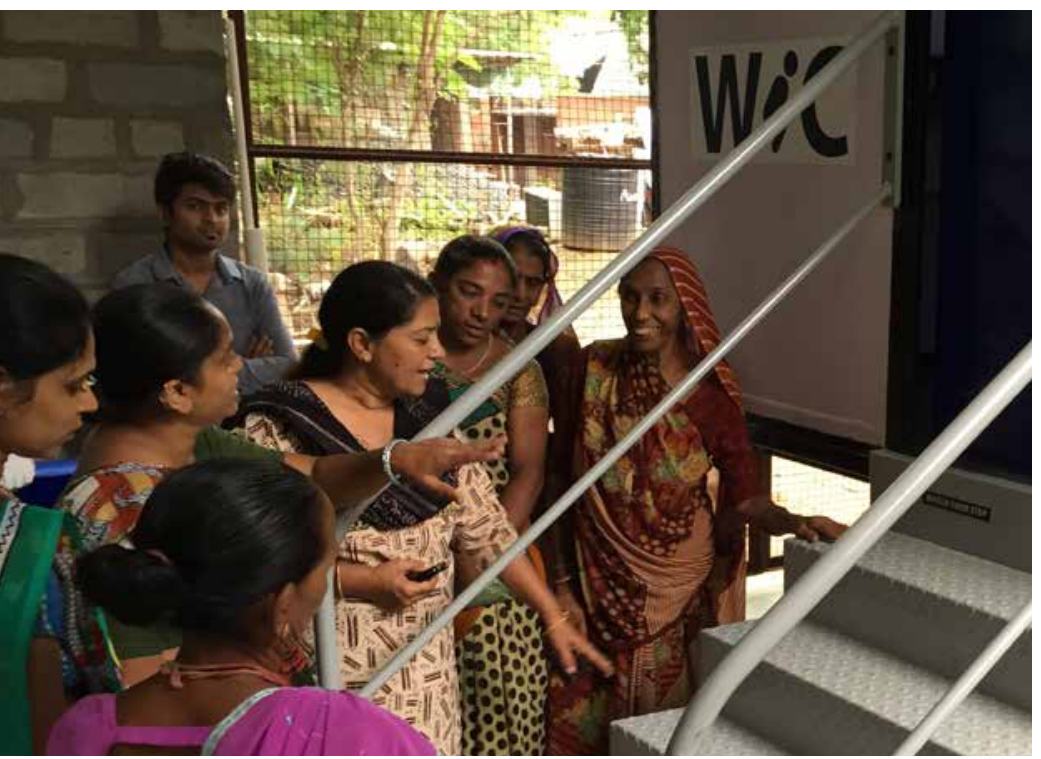

Worldwide, over 2.4 billion people do not use improved sanitation facilities, which minimize human contact with excreta and pathogens and reduce the risk of disease transmission. ${ }^{1}$ Given the global nature of the health, social, and environmental impacts of poor access to sanitation, significant efforts have been directed at research and development (R\&D) of sanitation technologies that treat waste for reuse and that function independently of the often cost-prohibitive sewered infrastructure. ${ }^{2}$ Notably, several recent early-stage R\&D efforts incorporate user preferences to encourage sustained adoption that is driven by user demand.

The Bill \& Melinda Gates Foundation's Reinvent The Toilet Challenge (RTTC) funds the development of toilet systems that remove pathogens, recover resources from waste, and process waste "off-grid" - that is, unconnected to sewer,

\section{Key Toilet Features That Influence User Demand}

Focus group discussions and survey data identified several strongly preferred features among respondents, many of which align with prioritized attributes (e.g., privacy, hygiene) of sanitation facilities.

- Gender-segregated stalls. Both men and women had a strong preference for gender-segregated stalls as a means for enhancing privacy and safety.

- Urinals. Men and women widely and equally favored urinals placed outside the toilet cabin. Men felt that urinals increase convenience, while women cited increased privacy and cleanliness inside the cabin when male traffic through the toilet was reduced. Men favored a partial closure around the urinal for privacy.

- Menstrual hygiene vending and disposal amenities. Men and women equally favored features that address increased vulnerability of women and girls during menstruation, such as options for private disposal and menstrual product procurement.

- Water provision. Availability of water for sanitation and other uses was an important factor in demand-driven facility use.

- Hand-washing provisions. Sinks for hand-washing and cleaning were highly valued and further increased in value when soap was provided.

- Aspirational features. Survey respondents indicated an interest in "modern" features, such as automatic flushing, mobile-charging, or in-stall radios. These features represent areas for further research on user demand and influence on technology adoption. 
electrical, or water systems. These systems target low-income populations underserved by improved, hygienic sanitation alternatives. The ongoing R\&D of systems funded under the RTTC improves technical performance and incorporates recommendations drawn from user-focused research. Most early-stage technology development and product engineering efforts do not reflect the users' experience; however, prevailing evidence suggests that technologies that do not reflect user preferences, beliefs, and attitudes may face significant barriers to adoption downstream. ${ }^{3}$ Thus, many RTTC systems aim to identify user preferences and incorporate meaningful findings into the systems' design and user interface.

This brief discusses user-centered findings that have helped guide the design of toilet technology funded under the RTTC (Figure 1). These findings broadly apply to other sanitation technologies seeking to incorporate user preferences in earlystage product engineering. Specifically, this brief draws on iterative rounds of data collection involving residents of low-
Figure 1. (a) The RTI toilet technology at the field-testing site in Ahmedabad, India. (b) Schematic representation of the RTI toilet's waste processing system.
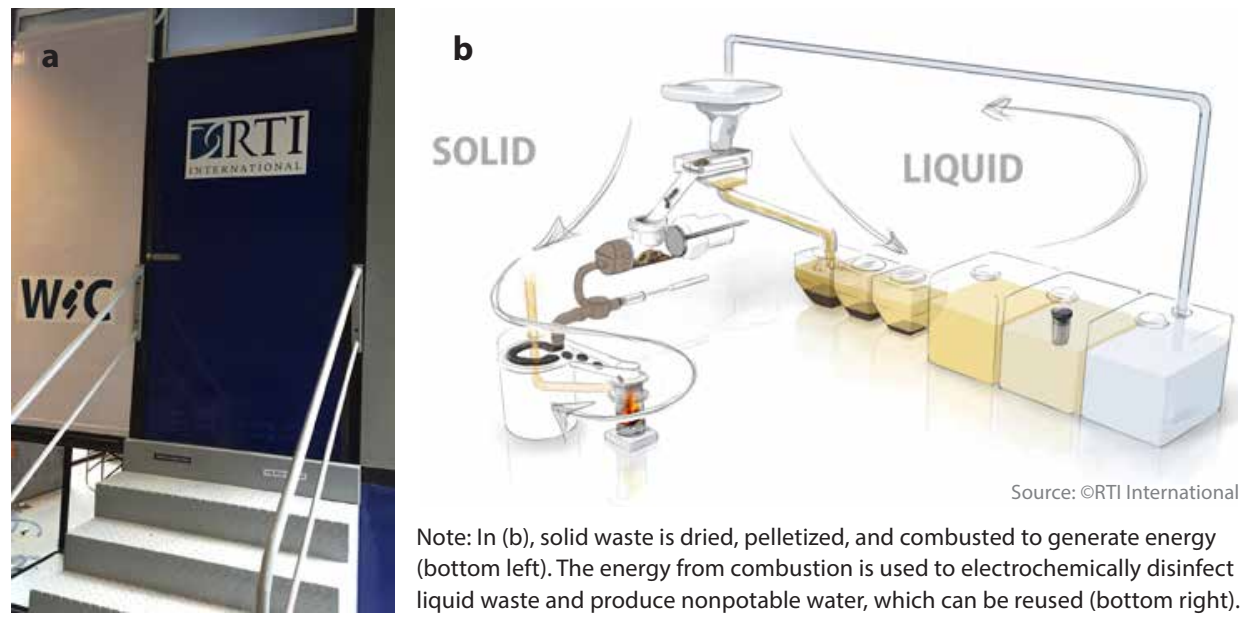

Note: In (b), solid waste is dried, pelletized, and combusted to generate energy (bottom left). The energy from combustion is used to electrochemically disinfect liquid waste and produce nonpotable water, which can be reused (bottom right).

\section{Table 1. User-centered data collected for research and development of the RTI toilet technology}

Household Survey

Focus Group Discussions

Number

1,213 households across 12 slum communities

Participants $50 \%$ male, $50 \%$ female by gender

Format* In-person survey conducted by SEWA research staff

60 discussion groups; 550 participants

$51 \%$ male, $49 \%$ female

In-person discussions segmented by gender and age, led by SEWA facilitators

\begin{tabular}{lll}
\hline Selection & Randomized & Recruited by SEWA \\
\hline Year & January-April 2015 & June and September 2014 \\
\hline Location & Ahmedabad, Gujarat & Ahmedabad and Vadodara, Gujarat \\
\hline $\begin{array}{l}\text { Focused } \\
\text { topics }\end{array}$ & $\begin{array}{l}\text { Current sanitation perceptions and } \\
\text { behaviors; attitudes toward sanitation } \\
\text { improvements; accessibility by women, } \\
\text { children, elderly, and disabled populations; } \\
\text { and a toilet attribute willingness-to-pay } \\
\text { choice experiment (menstrual product } \\
\text { disposal, water reuse) }\end{array}$ & $\begin{array}{l}\text { Treated water reuse, menstrual } \\
\text { hygiene management (MHM) } \\
\text { and women's sanitation, men's } \\
\text { sanitation practices and preferences, } \\
\text { sanitation improvements }\end{array}$ \\
& & \\
\hline
\end{tabular}

FGD = focus group discussion; SEWA = Self-Employed Women's Association.

* All data collection was completed in cooperation with India-based RTI research partner SEWA, a nongovernmental organization active in the communities that were surveyed. SEWA's trained research staff served as enumerators for the household survey and recruited participants for FGDs. In cases where content was deemed sensitive, we employed same-sex enumerators and FGD facilitators. income households in urban Gujarat, India (Table 1); we draw primarily from a household survey, and gain additional insight from focus group discussions (FGDs) conducted in advance of the survey.

\section{Importance of Users in Early- Stage Technology R\&D}

The importance of involving users in technology $R \& D$ has been widely acknowledged, ${ }^{4}$ but it has been largely overlooked and understudied regarding environmental health technologies such as improved latrines. ${ }^{5}$ Evidence suggests 6 that incorporating user preferences may encourage future adoption and sustained use of technologies. Because for many technologies an individual's decision to adopt is based on perceived costs and benefits of a technology's use, ${ }^{6}$ technologies that reflect user preferences are more likely to encourage user acceptance and adoption.

\section{Understanding Users and Adapting RTI's Toilet Technology}

Ongoing cycles of RTI toilet technology prototyping respond to information from user studies (summarized in Table 1), which gather insights from users on topics that may influence their adoption of new sanitation technology. Findings that represent strong and clear user preferences generate recommendations for system adaptation, while emerging themes generate topics for additional exploration in subsequent rounds 
of data collection with users. The 1,213-household survey (2015) built on findings from the FGDs conducted in 2014, and both informed recommendations for RTI's ongoing toilet technology engineering. In this brief, we prioritize survey findings given the survey's large sample size and randomized selection procedures.

The sample of survey respondents represented the target population of users of the RTI toilet technology. Participants

Table 2. Average respondent and household characteristics

\begin{tabular}{lll}
\hline Literacy rate & Male & Female \\
\hline Average educational attainment & $80.9 \%$ & $52.8 \%$ \\
\hline Average household size & Grade 8-10 & Grade 6 or 7 \\
\hline Average annual household income & $\begin{array}{l}\text { Rs.140,307 } \\
(\text { US\$2,193) }\end{array}$ & \\
\hline Receiving below poverty line & $82.2 \%$ & \\
government assistance & & \\
\hline Private piped water supply & $71 \%$ & \\
\hline Private household toilet & $66 \%$ & \\
\hline Hindu-majority communities & $66 \%$ & \\
\hline Muslim-majority communities & $9 \%$ & \\
\hline Low-caste-majority communities & $30 \%$ & \\
\hline
\end{tabular}

were resource-poor and socioeconomically disadvantaged (Table 2), relying heavily on open defecation and public or community toilets (Table 3). Additional characteristics, such as caste and religion, define important social communities within India. Relative to Indian Census data, the survey sample has, on average, lower literacy and income than average urban Gujarat residents. ${ }^{7}$ While ownership of private toilets is near-comparable with the state urban average of $74.3 \%$, open defecation is more than 3 times as prevalent among the survey sample, with $19.5 \%$ openly defecating compared with the state urban average of $6.2 \%$. High levels of open defecation among the survey population suggest that this population may benefit from improved sanitation alternatives, such as the technologies developed under the RTTC; therefore, these communities hold important insights to guide the development of these sanitation technologies.

\section{Guidance for Technology Engineering and Design}

The survey findings summarized below represent important user adoption considerations related to attributes, services, and amenities of a toilet system (Table 4), with additional insight provided from FGD data and related findings from the literature. In each case, we offer guidance for engineering and design of sanitation products and technologies.

\section{Table 3. Sanitation facility characteristics}

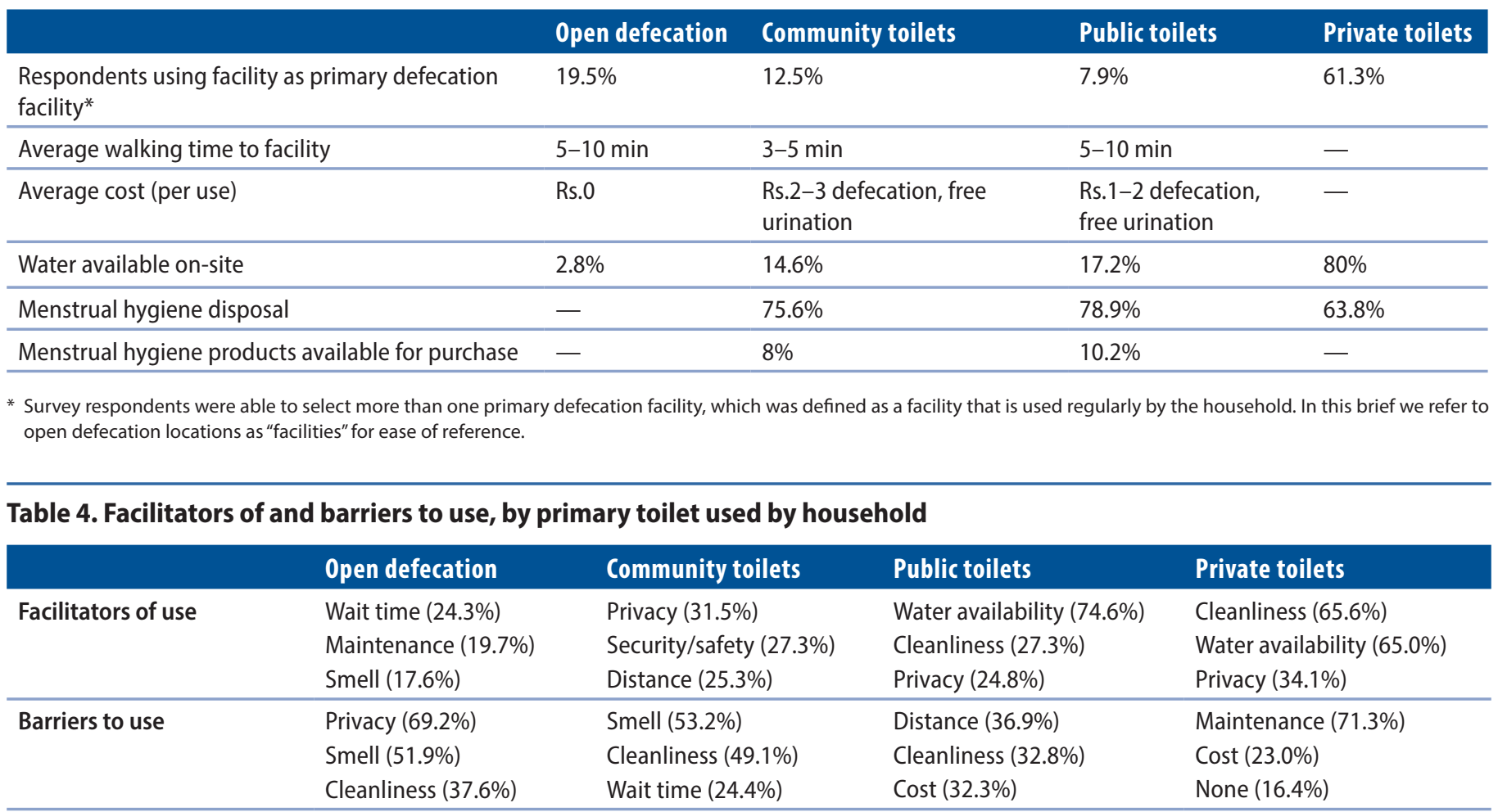




\section{Privacy}

Privacy is highly prioritized among users and valued equally among men and women respondents. Survey data suggest that, in particular, privacy plays a key role in encouraging use of enclosed facilities rather than open defecation, for which lack of privacy is an important deterrent (Table 4). FGDs confirm this finding and suggest that privacy is broadly associated with safety, dignity, and prestige. ${ }^{8}$ A qualitative study of community toilet initiatives in India also found a strong desire for privacy and designers modified cabin layouts in response to this priority. ${ }^{9}$ Specifically, the study found preferences for positioning stall doors facing away from the main entrance and creating separate entrances for men and women.

Design features that prioritize user privacy are important. However, while some features make clear improvements to privacy, design decisions should also consider how features may align or conflict with other sanitation priorities-for example, introducing higher stall doors may satisfy the desire for privacy but conflict with preferences for lighting or ventilation.

\section{Safety}

Safety from violence and harassment is an important motivation for using a built facility for defecation, and is a desirable feature of community toilets. Among groups reliant on open defecation, the motivation to increase privacy was particularly pronounced. While reported incidence of harassment and attack at sanitation sites among the survey sample was less than $10 \%$, safety at night was a concern, particularly among women and girls. While two-thirds of respondents felt that women and girls were safe during the day at open defecation sites, only $30 \%$ believed that women and girls were safe at night. This finding confirms those of earlier focus groups, in which participants discussed the ways they tried to stay safe; for example, women would travel to toilets in groups or with men from their households. ${ }^{8}$ Existing qualitative studies on sanitation suggest that provisions for safety are widely lacking in urban areas. ${ }^{10}$ Thus, prioritizing and understanding amenities and services that make users feel safer (e.g., lights, locks, attendants) are important considerations.

\section{Cleanliness/Hygiene}

Survey respondents highlighted cleanliness as an important attribute and determinant of use for all shared facilities.

Among community toilet users, nearly $50 \%$ perceived them to be badly maintained and cited hygiene as a concern. Users of community and public toilets strongly preferred facilities that were serviced and cleaned daily. Focus group discussions corroborated the findings that participants prioritized cleanliness over nearness; further, some thought that lack of cleanliness led to illness. ${ }^{8}$ The existing literature shows that, across urban and rural settings alike, cleanliness of sanitation facilities matters. ${ }^{11}$ Therefore, maintenance protocols or services should be stipulated for sanitation facilities. To facilitate adoption, users must perceive new facilities as clean relative to existing options.

\section{Distance}

Survey findings show that distance and convenience are important factors influencing facility use. Having a short distance to travel between a sanitation facility and an individual's household was important to users, especially among women using public toilets during menstruation. On average, survey respondents who use public toilets had to walk 5-10 minutes each way, although estimates from FGDs found travel times of more than 1 hour in some urban settings. ${ }^{8}$ In India, the distance to improved sanitation facilities has emerged as a priority issue, particularly because it has been correlated with safety and violence against women. ${ }^{12}$ Thus, while product engineering may not always determine location, location and distance from users' households should be considered and prioritized when applicable, particularly as technologies mature.

\section{Water Availability}

The presence of water and its availability for uses on- and off-site are among the most important amenities at sanitation facilities and increase user demand for a facility. Survey responses suggest that where water is available, it is a key driver of facility use; conversely, where water is unavailable, it is a barrier to use. Figure 2 demonstrates that, at facilities where water is available, respondents often collect the water for a variety of other purposes. Uses for water gathered at sanitation facilities vary widely by respondent background and primary sanitation facility, but most commonly, water is used for on-site cleansing and drinking. Insights from $\mathrm{FGDs}^{8}$ agree with findings in the literature, ${ }^{13}$ which suggest that water use is determined by its perceived quality, of which appearance (e.g., color, turbidity) and odor are important indicators. Studies in rural India have noted large-scale improvements in toilet adoption and health when sanitation and water supply initiatives are implemented simultaneously. ${ }^{14}$ Thus, systems that make water available to users for a variety of purposes can help sustain or increase user demand. Additionally, attention to water quality with regard to its intended uses is important.

\section{Menstrual Hygiene Management}

Menstruation often influences women's use of sanitation facilities. During menstruation, women seek out and are more likely to use sanitation facilities that are close to home, 
hygienic, and have adequate disposal options. Approximately $10 \%$ of female respondents of menstruating age suggested that they change their primary defecation facility during menstruation, a trend that was most common among survey respondents who primarily use public toilets or open defecation. Respondents who switched from their primary facility to a different facility during menstruation cited unhygienic conditions and long travel time as motivations for seeking out a different facility. Additionally, women seek private areas for washing and drying of reusable menstrual products, such as cloths. Thus, efforts to improve facilities to reflect women's needs during menstruation may generate more sustained use.

The survey additionally found that designated disposal mechanisms for menstrual hygiene products are rare in most shared facilities, and that standard (undesignated) garbage bins are not consistently available across sanitation sites. FGDs echo this finding, ${ }^{8}$ and additional field studies ${ }^{15}$ cite a need for greater discretion and privacy for disposal. Findings from the choice experiment included in the household survey indicate moderate acceptance of incineration to dispose of menstrual hygiene management products, although preferences vary widely across contexts and demographic groups.

Menstrual hygiene products are widely unavailable for purchase in sanitation sites used in the sample; on average, they are available in $8 \%$ of community toilets and $10 \%$ of public toilets. Studies of gender-responsive sanitation system design suggest that offering these products could increase women's use of facilities. ${ }^{16}$ Approximately $40 \%$ of women surveyed used disposable pads rather than reusable cloths; disposable products were correlated with greater wealth, older age, and higher levels of education. This suggests that, affordability constraints aside, disposable pads could be aspirational, and a vending provision may help stimulate demand for use of a facility.

\section{Water Reuse}

The RTTC challenges systems to introduce renewable components to system design. Disinfected water is one renewable resource that can be drawn from human waste processing; however, RTTC teams incorporating reusable water should consider the potential barriers to adoption when reused water is introduced. A choice experiment included in the household survey found, first, considerable variation in attitudes toward water reuse and, second, that across the full sample, reused water was acceptable for only explicit applications. Respondents positively viewed reuse of water from the RTI toilet system for handwashing and anal cleansing, but more strongly preferred it for noncontact uses, such as flushing. Users are often amenable to water reuse if it does not conflict with cultural and religious values; reflects affordable, financially beneficial improvements to water access and quality; and requires little knowledge to understand. ${ }^{17}$ Importantly, users' willingness to accept reused water may extend beyond its potability-they may have concerns about appearance and odor as well as quality. ${ }^{2}$

\section{Conclusions}

Gathering user-focused insights early in the product engineering and design process provides an important opportunity to identify and avoid potential downstream barriers to technology adoption. This brief provides an overview of influential design considerations (e.g., cleanliness, hygiene) and high-level guidance for incorporating these considerations into product engineering and design (e.g., maintenance protocols).

The user preferences discussed represent several contexts in urban India, in Gujarat state. However, even within similar contexts and groups of respondents, unique and often varying preferences persist. Those designing sanitation technologies for a range of settings need to account for the array of preferences of many different users and should conduct studies within the population of users they intend to serve. As technologies adapt to serve specific subgroups, such as women, the elderly, 
disabled people, and children, technology designers and engineers should consider that sanitation preferences and needs may also change.

Continuously gathering feedback from users allows for ongoing improvement of the technology being designed. Findings in this brief influenced the design of the RTI toilet technology and introduced efficiencies into the technology's R\&D efforts. Early and ongoing consideration of users is important for other sanitation technology design efforts, as well.

\section{References}

1. WHO/UNICEF Joint Monitoring Programme for Water Supply and Sanitation. Progress on sanitation and drinking water: 2015 update and MDG assessment. 2015. Available from: https://www.unicef.org/ publications/index_82419.html

2. Katukiza AY, Ronteltap M, Niwagaba CB, Foppen JW, Kansiime F, Lens PN. Sustainable sanitation technology options for urban slums. Biotechnol Adv 2012;30(5):964-78. https://doi.org/10.1016/j.biotechadv.2012.02.007

3. Joshi D, Fawcett B, Mannan F. Health, hygiene and appropriate sanitation: experiences and perceptions of the urban poor. Environ Urban 2011 Apr;23(1):91-111. https://doi.org/10.1177/0956247811398602

4. Harrison MI, Koppel R, Bar-Lev S. Unintended consequences of information technologies in health care-an interactive sociotechnical analysis. J Am Med Inform Assoc 2007;14(5):542-9. https://doi. org/10.1197/jamia.M2384

5. Seymour Z, Hughes J. Sanitation in developing countries: a systematic review of user preferences and motivations. J Water Sanit Hyg Dev 2014 Dec;4(4):681-91. https://doi.org/10.2166/washdev.2014.127

6. Pattanayak SK, Pfaff A. Behavior, environment, and health in developing countries: evaluation and valuation. Annu Rev Resour Econ 2009;1(1):183217. https://doi.org/10.1146/annurev.resource.050708.144053

7. National Sample Survey Office. [Key Indicators of drinking water, sanitation, hygiene and housing condition in India, July 2012-December 2012]. Ministry of Statistics \& Programme Implementation, Government of India. 2013 Dec. Available from: http://www.icssrdataservice.in/ datarepository/index.php/catalog/95/download/1238

8. RTI International. RTI Reinvent the Toilet summary field report: September 2014 user studies, Gujarat State. 2015. Available from: http:// abettertoilet.org/wp-content/uploads/2015/02/Sept-2014-User-Studies_ Summary-Final-Report-Jan2015.pdf

9. Burra S, Patel S, Kerr T. Community-designed, built and managed toilet blocks in Indian cities. Environ Urban 2003 Oct;15(2):11-32. https://doi. org/10.1177/095624780301500202

10. Lennon S. Fear and anger: perceptions of risks related to sexual violence against women linked to water and sanitation in Delhi, India-briefing note. London, UK: Sanitation and Hygiene Applied Research for Equity and WaterAid, UK; 2011.

11. Seymour Z, Hughes J. Sanitation in developing countries: a systematic review of user preferences and motivations. J Water Sanit Hyg Dev 2014 Dec;4(4):681-91. https://doi.org/10.2166/washdev.2014.127
12. Bapat M, Agarwal I. Our needs, our priorities; women and men from the slums in Mumbai and Pune talk about their needs for water and sanitation. Environ Urban 2003 Oct;15(2):71-86. https://doi. org/10.1177/095624780301500221

13. de França Doria M. Factors influencing public perception of drinking water quality. Water Policy 2010 Feb;12(1):1-19. https://doi.org/10.2166/ wp.2009.051

14. Duflo E, Greenstone M, Guiteras R, Clasen T. Toilets can work: short and medium run health impacts of addressing complementarities and externalities in water and sanitation. National Bureau of Economic Research Working Paper No. 21521. 2015 Sep. Available from: http://www. nber.org/papers/w21521 https://doi.org/10.3386/w21521

15. Kjellen M, Pensulo C, Nordqvist P, Fogde M. Global review of sanitation system trends and interactions with menstrual management practices. Stockholm Environment Institute. 2012 Apr. Available from: https://www. sei.org/publications/global-review-of-sanitation-system-trends-andinteractions-with-menstrual-management-practices/.

16. Hartmann M, Krishnan S, Rowe B, Hossain A, Elledge M. Genderresponsive sanitation solutions in urban India. RTI Press Publication No. RB-0009-1502. Research Triangle Park, NC: RTI Press; 2015 Feb. https:// doi.org/10.3768/rtipress.2015.rb.0009.1502

17. Laban P. Can local people accept greywater technology? In: McIlwaine S, Redwood M, editors. Greywater use in the Middle East: technical, social, economic and policy issues. Ottawa, ON: International Development Research Centre; 2010. p. 101-111. https://doi. org/10.3362/9781780440224.007

\section{About the Authors}

Laura Morrison, MPP, is a research economist in RTI International's Center for Environmental, Technology, and Energy Economics.

Anushah Hossain, BA, is a graduate student in the Energy and Resources Group at the University of California-Berkeley.

Myles Elledge, MPIA (Master of Public and International Affairs), was a senior director in RTI's Center for Engineered Systems at the time of writing. He is now executive director of Health \& Environment at Biomass Controls.

Brian Stoner, $\mathrm{PhD}$, is a research professor in Electrical and Computer Engineering, Duke University.

Jeff Piascik, PhD, is president at Biomass Controls.

RTI Press Research Briefs and Policy Briefs are scholarly essays on policy, methods, or other topics relevant to RTI areas of research or technical focus.

RTI International, 3040 East Cornwallis Road, PO Box 12194 Research Triangle Park, NC 27709-2194 USA

+1.919.541.6000_rtipress@rti.org_www.rti.org

(O2018 RTI International. RTI International is a registered trademark and a trade name of Research Triangle Institute. The RTI logo is a registered trademark of Research Triangle Institute.

cc)(1)(-) $($ This work is distributed under the terms of a Creative Commons cc. Attribution NonCommercial-NoDerivatives 4.0 license (CC BY-NC-ND), a copy of which is available at https://creativecommons.org/ licenses/by-nc-nd/4.0/legalcode.

www.rti.org/rtipress 